\title{
Reducing the environmental impact in the metal finishing industry by employing cleaner and safer production strategies
}

\author{
G. Raymond, E. Piatyszek \& V. Laforest \\ Department of Sciences, Information, and Technologies for Environment, \\ École des mines de Saint Etienne, France
}

\begin{abstract}
Cleaner production strategies are being implemented by the metal finishing industry, in the face of increasingly strict pollution regulations as well as to deal with a permanent need to innovate. These preventive measures have a positive impact on the competitiveness of these firms as well as the environment. This is due to the diminished use of raw materials, lower energy consumption, subsequent reduction of contaminated materials and outflow, as well as inherently lessening the risks or hazards of environmental pollution. However, employing diverse, cleaner production methods is complex. Moreover, this can have a negative effect especially when the entire situation is taken into account, demonstrating the need for effective decision aids in this sector.

This paper presents the conception of a diagnostic tool for cleaner and safer production (CSP) impacts. The proposed tool is based on a system of CSP indicators, which quantifies the firm's overall impacts and estimates the level of risk generated.

The main issues of this work are:

-Environmental: considering whether the tool will help reduce firms' impacts -Regulatory: because this approach helps industry to comply with existing legislation and anticipate new constraints

-Safety: taking into account risks generated by the implementation of CSP practices.
\end{abstract}

This decision aid can be used in choosing a CSP set up strategy as well as to promote innovation initiatives.

Keywords: cleaner and safer production (CSP), impact assessment tool, environmental management decision aid, metal finishing. 


\section{Introduction}

The concept of cleaner production sprang from an increasing awareness of the negative environmental impacts generated by manufacturing processes and their products. This led, therefore, to an urgent need to reduce these effects. Cleaner production, as defined as "the continuous application of an integrated preventive environmental strategy to processes, products, and services to increase overall efficiency, and reduce risks to humans and the environment" [1, 2], can be applied to the processes used in any industry, the products themselves and to the various services provided. Currently, cleaner production strategies are being implemented by the metal finishing industry, in the face of increasingly strict pollution regulations as well as to deal with a permanent need to innovate. The implementation of these new production strategies can generate significant modifications for enterprises. Therefore, to assist the cleaner production set up, it is necessary to develop solutions that can accurately help professionals to take appropriate decisions when a modification is needed. The methodology and the decision aid the authors are developing will provide metal finishing companies with a clearer appraisal of their conformity with regulations, as well as to identify and quantify the impacts of implementing cleaner production strategies. In addition, this tool will estimate the risks linked to the industrial processes.

The present article is about the initial steps for the creation of our decision aid. Section 1 presents the French metal finishing industry sector and the regulatory pressures it faces. Then, section 2 gives an overview of the existing approaches for impact assessment tools. In the next section the necessity for a cleaner and safer production (CSP) impact assessment tool is justified, the structure of which should based on indicators as well as a systemic approach. The fourth section concerns our initial results and finally conclusions are presented in section 5 .

\section{Metal finishing industry and pertinent regulations}

\subsection{Metal finishing sector}

Metal finishing is about modifying the metals' surface properties by their treatment with chemical, electrochemical, and/or mechanical processes. In general, these processes confer new anti-corrosion, anti-wear, and esthetical properties to the metal surface. Among the diverse types of existing treatments, resurfacing represents $43 \%$ of this sector, following by painting (31\%), finally followed by converting [3,4]. Despite a significant turnover or volume, evaluated at 4 billion euros in 2003, the metal finishing sector is declining. This is due to the presence of too many finishing workshops with respect to clients, diminution of technical activities in Europe, and growth of substitution options as well as industrial outsourcing. Consequently, enterprises in this sector constantly need to innovate to improve their competitiveness and satisfy their customers [4]. 


\subsection{Pollution and risks in metal finishing workshops}

The use of toxic chemicals in surface finishing makes this sector a potential hazard for workers, ecosystems, and the population in general as well as presenting a risk to property [5]. The risks depend on the nature of the substances used, the operations and on the conditions of the CSP implementation [6].

Principal risks for workers are intoxication, allergic reactions or even the development of cancer.

At environmental level, the risk of soil and water pollution is linked to leakage in the pipes or baths. Pollution generated by aqueous surface finishing is diverse. Main pollutants come from reagents used or the products of the reaction. They can be acids or bases, heavy metals (non degradable), organic matter, suspended solids, cyanides, water enrichment compounds, salts $[6,7]$.

The airborne pollution generated by surface finishing plant is composed of solid particles, volatile organic compounds, and toxic molecules that can poison or provoke allergic reactions via the contamination of vegetables and the water supply.

As for property risk, explosions, exothermic and/or gaseous reactions, as well as fire are major risks due often to the storage of flammable substances.

\subsection{French legislation as applied to the metal finishing industry}

Metal finishing industries must comply with the European Directive 96/61/EC (IPPC) when their treatment bath volume exceeds $30 \mathrm{~m}^{3}$ [8]. This directive has been incorporated into French legislation via existing rules as well as new measures. French Law as regards to the environment is either by type (water, air, waste...) or an integrated approach. The latter is for officially identified sites for the protection of the environment (ICPE). This organisation is responsible for monitoring and controlling pollution and dangerous activities. Metal finishing enterprises are subject to this legislation. The characteristics for each enterprise determine their classification whether they are subject to declaration (D), authorization (A) or authorization with public utility servitude (AS). To obtain the authorization, a dossier, containing impact, danger and waste studies, is required. A and AS metal finishing enterprises have to comply with the ministerial order of the $30^{\text {th }}$ of June 2006. This defines the technical and administrative constraints whose goal is to limit pollution, nuisance and risks generated by the firms. [8] This order sets the emission limit values of authorized emissions, specific flow-rate ( 8 liters $/ \mathrm{m}^{2}$ of treated surface/ rinsing function), and monitoring rules for the enterprises to follow. The order also specifies actions to prevent and reduce noise, to closely keep an eye on groundwater and soil, and to rectify any on-site soil or groundwater contamination in the event of a factory or plant closing $[9,10]$.

\section{State of the art on existing approaches concerning impact assessment tools}

Several environmental assessment tools are available and described in literature [11-14]. However, if literature abounds with impact assessment tools, with 
different characteristics there seems none dealing with the CSP. A brief and non exhaustive overview is as follows:

First, assessment tools can be quantitative or qualitative.

Assessment methods can also be characterized by their approach perspectives, of which there are two: site and product approach. The site approach is from a geographical point of view. Thus, an assessment method based on this method is limited to the production site or its surroundings. These methods are often used as internal management tool of enterprises, based on continuous improvement principle. The product approach goes well beyond the firm's walls, as it takes account of several steps of the product life cycle. Indeed, the objective is to quantify the fluxes of matter and energy along or on a part of the product life cycle, and assess their potential impacts.

Another important characteristic of assessment tools is their mono or multicriteria aspects. In the mono-criterial approach only the impact of one aspect is evaluated. For example, the "Bilan Carbone" method developed by the French Environment and Energy Management Agency (ADEME) in 2004, proposes to evaluate the greenhouse gases emission GES generated directly or indirectly by human activities [11]. This method quantifies greenhouse emissions with readily available data. It is easy to see how this approach makes people aware of greenhouse emissions. Despite of the convenience, the "Bilan Carbone" doesn't take into account the whole impact on the environment [15]. Contrarily, multicriteria assessment tools do evaluate numerous aspect and their impacts. To illustrate, Life Cycle Assessment (LCA), treats different impacts like GHS, eutrophication, photochemical smog's...LCA, the most recognized assessment method internationally, is about the environmental impact evaluation for all the activities associated with a given product or service, throughout its lifespan [16]. LCA is a quantitative and complete approach, which however requires a great deal of information, and a relatively long time to collect the data. In addition, LCA doesn't take in account the local environment as it is a holistic approach, and can not integrate completely sustainable development principles because social and economic criteria are not included [15].

The originality of our proposed cleaner and safer production impact assessment tool project lies in the fact that, currently, a CSP impact decision aid seems to be non-existent. Moreover, the notion of risk is rarely associated with environmental assessment methods. The site approach appears well adapted for our tool taking into account local impacts on firms and their surroundings. Furthermore, a multi-criteria approach is required to have an overview of the differing impacts resulting from the CSP set up. Finally our approach, based on CSP indicators will include both qualitative and quantitative aspects.

\section{A tool based on CSP indicators as well as the systemic approach}

\subsection{Systemic approach}

A systemic approach can be applied to analyse enterprise organisations and mechanisms. Indeed, "an enterprise is a dynamic combination of human, 
technical and financial resources, combined to bring about, through its organisation, the accomplishment of its fundamental goals". This organisation is manifested with and applied by its communication [17]. Consequently, an enterprise is a complex system whose mechanisms involve very many interactions among people, products and machines [18, 19].

Furthermore, systemic approach to structure the CSP indicators considers the causal mechanisms of phenomena in the expectation of an overall and complex representation of actual situations. An indicator is a simplified view of reality, which is expected to reflect complex and diffuse phenomena [20]. The causal relationships between indicators appear tacitly in the different existing indicators models, which lead to abut side by side these indicators in different categories [21]. The use of systemic concepts would make explicit these relationships [19]. The use of a systemic approach appears appropriate for our impact assessment tool.

\subsubsection{MADS model (Method Analyse Dysfunctions in the System)}

The MADS model was developed in order to foresee or prevent major-accident hazards or risks in sophisticated industrial plants or processes, which were not easily grasped with classical risk analysis methods (Bhopal, Tchernobyl, Seveso...) [5]. This tool is based on the systemic modelling principles. The universe of danger and (near-failures) is composed a source and target for the danger system, which immersed into an active environment. Together material, energy and information fluxes are exchanged [22, 23]. In this model, the fluxes of danger are faults that provoke undesirable effects on their targets (workers, population, ecosystem, plant buildings etc [24]. These fluxes are triggered by event at the danger sources, and lead to an accident or undesirable event resulting from their impacts on the targets [22].

The use of MADS model seems to be well adapted for structuring CSP indicators. Indeed an analogy can be made in the case of a cleaner production practices such as a process modification. This modification is the triggering event (hazard), which has an impact on the enterprise and its surroundings (targets). Furthermore, the MADS model allows a systemic evaluation of enterprises by breaking them down into potentially subsystem targets of a cleaner production practice. This decomposition is made by using table system danger sources. This can identify the targets (Table 1).

The target systems for a CSP practice are the firm and surroundings that has set this up The firm's environment is composed of five target subsystems:

- Population living around the site,

- Ecosystems,

- Enterprise' clients and suppliers.

- Governmental authorities

Within the enterprise system, the targets sub-systems are:

- The workers,

- Operations,

- Enterprise' s internal strategy 
Table 1: $\quad$ Target systems.

\begin{tabular}{|c|c|}
\hline Target System & Subsystem \\
\hline \multirow{4}{*}{ ENVIRONMENT } & Population \\
\cline { 2 - 2 } & Ecosystem \\
\cline { 2 - 2 } & Clients \\
\cline { 2 - 2 } & Suppliers \\
\cline { 2 - 2 } & Authorities \\
\hline \multirow{4}{*}{ ENTERPRISE } & Workers \\
\cline { 2 - 2 } & Operations \\
\cline { 2 - 2 } & $\begin{array}{c}\text { Enterprise } \\
\text { strategy }\end{array}$ \\
\hline
\end{tabular}

This MADS approach creates a simple model of the enterprise, in order to easily identify and structure the indicators which will assess the CSP impacts. Moreover, this approach is also a risk analysis method, that's the reason why the tool will consider the risks inherent in cleaner production practices.

\subsection{A tool based on CSP indicators}

\subsubsection{The use of indicators}

Literature suggests numerous definitions for the notion of an indicator. The European environmental agency defines an indicator as "a measure, generally quantitative, which can be used for illustrate and simply communicate complex phenomena, including tendencies and progress by the time" [25]. Indicator objectives are threefold [26]:

-To raise awareness and understanding by simplifying the information thus rendering it comprehensible. The chosen indicator number should be optimized. Indeed too many indicators make the obtained results look confusing and hence obscure the overview. At the same time, the simplification of information achieves an objective view, but usually provides an incomplete vision of actual situation: "Indicators give a simplified view of realty, which is supposed to mirror complex and diffuse phenomena" [20].

-To help decision-making. The primarily function of an indicator is to be a decision aid to evaluate firms' performances [27]. The nature of the decision, context of the decision-making, and also parties involved will obviously modify the nature of the required indicators [28].

-To measure progress toward established goals. Indicators have to assess a scalable situation or an action and its consequences, and compare their states at different times [29]. Furthermore, an indicator's hit-and-miss depends on the continuously changing context into which it was developed and for which it has to suit.

Consequently, a tool based on indicators is well adapted for this project because the indicator's objectives suit perfectly the long-term goals of the goals 
of our project. Indeed, the authors want to develop a decision-making aid that will quantify the impacts of the enterprise activities and evaluate the existing risk (To raise awareness and understanding), before and after the CSP strategy set up (To measure progress toward established goals).

Beyond this notion of indicators, the concepts of criteria, index, and parameters are required for this work. The definition of these notions links or reveals the relations among them (Figure 1).

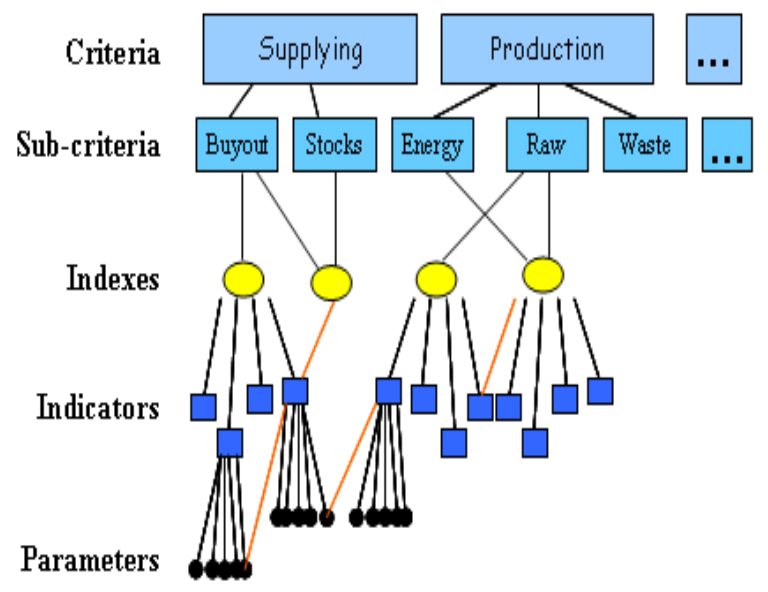

Figure 1: Relation between the different notions.

Criteria are characters for which people refers to, in order to get a handle on the subject. Criteria are informed by indexes that are the effect of the aggregation of indicators. These indicators are themselves built from parameters, which are measures of the concerned phenomena. The use of these notions has two objectives:

- Make information understandable

- Structure information given by parameter.

The criteria on which we refer on, to assess CSP impacts, were defined for each sub-system of the MADS model.

\subsubsection{Selection of CSP indicators}

Cleaner and safer production indicators seem to be difficultly identifiable and poorly structured in literature. The CSP indicator construction is based on the work of Cerruti [30], who presented a method to build indicator scorecards.

First, CSP indicators and parameters were identified, based on other concepts like sustainable development, eco-efficiency, environmental performance assessment or security already proposed in the literature. The goal was to obtain the most complete list of indicators and parameters that could be reemployed to assess CSP. At the same time, a regulatory context study and visits to surface finishing workshops lead to the identification of indicators specific to this sector. At the end, a prospective list of 200 indicators was obtained [14]. 
As aforementioned in the section 3.2, too many indicators make the obtained results confusing. Consequently, the second step of the selection work was to sort out the most relevant indicators to CSP assessment. The degree of excellence for an indicator depends on diverse requirements. Mainly, indicators have to describe reliably the phenomena concerned, by furnishing information that answer a need or objective. Information should be comprehensible and are easily brought up to date in order to follow progress towards the objectives. Accessibility to the parameters is also required [14]. After successive sorting, the number of CSP indicators was reduced to 50. The following step of the Cerruti's method consists in the combining these indicators in order to reveal an indicator corpus or indexes representative of the phenomena. These indexes fulfil the assessment criteria.

Table 2: $\quad$ CSP indicators structure.

\begin{tabular}{|c|c|c|c|c|c|c|}
\hline $\begin{array}{l}\text { Target } \\
\text { system }\end{array}$ & $\begin{array}{l}\text { Sub- } \\
\text { system }\end{array}$ & Criteria & Sub-criteria & Index & Indicators & Parameters \\
\hline \multirow{16}{*}{ 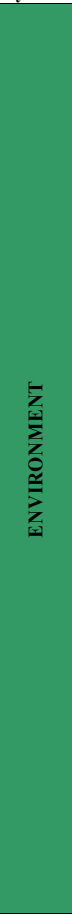 } & \multirow[b]{3}{*}{ Population } & \multirow[t]{2}{*}{ Nuisance } & Noise & - Noise measure & - Noise measure & $\begin{array}{l}\text { - Measured noise level } \\
\text { - Regulatory noise level }\end{array}$ \\
\hline & & & Odour & - Odour level & -Odour level & - Concentration of odour \\
\hline & & Toxicity & Accident & - Gravity index & $\begin{array}{l}\text { - danger index for thermal flux } \\
\text { effect } \\
\text { - danger index for a } \\
\text { overpressure flux effect } \\
\text { - danger index for liquid } \\
\text { toxicity flux effect }\end{array}$ & \\
\hline & \multirow{11}{*}{ Ecosystem } & \multirow{7}{*}{ Water } & \multirow{6}{*}{ Wastewater } & \multirow{5}{*}{$\begin{array}{l}\text { - Regulatory } \\
\text { agreement index }\end{array}$} & - $\mathrm{pH}$ of effluents & $\cdot \mathrm{pH}$ \\
\hline & & & & & - Effluents' temperature & - temperature \\
\hline & & & & & $\begin{array}{l}\text { - toxic and metallic charge in } \\
\text { effluents }\end{array}$ & $\begin{array}{l}\cdot \text { - metal concentration in } \\
\text { the effluent }\end{array}$ \\
\hline & & & & & - pollutant charge in water & $\begin{array}{l}\text { - MES COD, } \mathrm{BOD}_{5}, \mathrm{~F}, \\
\text { AOX, hydrocarbures, } \mathrm{P} \text {, } \\
\text { global Nitrogen }\end{array}$ \\
\hline & & & & & - specific consumption & - specific consumption \\
\hline & & & & $\begin{array}{l}\text { - Biodegradability } \\
\text { index in water }\end{array}$ & $\begin{array}{l}\text { - Biodegradability index in } \\
\text { water }\end{array}$ & \begin{tabular}{|l|l|} 
& $\mathrm{DCO}$ \\
$\cdot \mathrm{DBO}_{5}$ \\
\end{tabular} \\
\hline & & & Consumption & $\begin{array}{l}\text {-Indicator of water } \\
\text { intensity }\end{array}$ & - Indicator of water intensity & $\begin{array}{l}- \text { Volume of water used } \\
\text { - production }\end{array}$ \\
\hline & & \multirow{3}{*}{ Air } & \multirow{3}{*}{ Pollution } & \multirow{2}{*}{$\begin{array}{l}\text { - Atmospheric } \\
\text { pollution index }\end{array}$} & - Greenhouse gases emission & \\
\hline & & & & & $\begin{array}{l}\text { - Emission of acidification } \\
\text { substances }\end{array}$ & \\
\hline & & & & $\begin{array}{l}\text { Toxic and metallic } \\
\text { charge in the } \\
\text { gaseous effluents }\end{array}$ & $\begin{array}{l}\text { - toxic, metallic and pollutant } \\
\text { charge rejected in the air }\end{array}$ & $\begin{array}{l}\text { - pollutants concentration } \\
\text { in the gaseous effluents }\end{array}$ \\
\hline & & Soil & Pollution & - Gravity index & $\begin{array}{l}\text { - danger index for thermal flux } \\
\text { effect } \\
\text { - danger index for a } \\
\text { overpressure flux effect } \\
\text { - danger index for liquid } \\
\text { toxicity flux effect } \\
\end{array}$ & \\
\hline & \multirow[t]{2}{*}{ Clients } & \multirow[t]{2}{*}{ Quality } & \multirow[t]{2}{*}{ Satisfaction } & \multirow[t]{2}{*}{-Quality index } & •client satisfaction & $\begin{array}{l}\text { - Number of claims } \\
\text { - Number manufactured } \\
\text { pieces }\end{array}$ \\
\hline & & & & & - anticorrosive characteristics & $\begin{array}{l}\text { - Number of hours without } \\
\text { oxidation }\end{array}$ \\
\hline
\end{tabular}

\section{Results}

The first results of this organisational work are shown in table 2. The environment target system is only partially presented here. For each sub-system target, evaluation criteria are defined. For example the main criteria from which the evaluation of impacts on ecosystems will be accomplish, are water, air, and 
soil. Then, these criteria are subdivided into sub-criteria in order to clearly define and structure the CSP indicators. Two sub-criteria seem to be relevant for the criteria "Water", "water consumption" and "water effluents". They respectively characterise the impact of the use of the water as well as extent of wastewater after use. The fifth column presents the indexes that are required to fulfil the criteria. As can be seen, the same index can be use to assess criteria. For example, the "gravity index" allows simultaneously the evaluation of the toxicity criteria for population and also the soil pollution for ecosystems. This shows the dependence links between the criteria. And finally indicators and parameters presented in the sixth and seventh column, provide for theses indexes.

\section{Conclusion and remarks}

Cleaner production has proven itself as an effective way of improving utilisation of materials, reducing contaminated materials and outflow, lowering energy consumption, as well as inherently lessening the risks or hazards of pollution into the environment. However with the implementation of any complex procedure there is real risk that while seemingly reducing cost or pollution in one area, the overall effect might be negligible or even negative. Therefore, it is necessary to develop tools that can accurately estimate the whole or broad impact of employing the diverse techniques of cleaner production.

This paper summarizes the initial steps in this effort, which involved the identification of cleaner and safer production impacts that could be dealt with through a set of cleaner and safer production indicators. These impacts are identified through the use of a risk analysis method, the MADS model, which can identify potential sensitive targets of a CSP practice. The use of a systemic model to structure the indicators can emphasize the relationship among them. The first results of the ongoing organisational work were presented and described. The future work will consist of:

- Validating the presented indicators through industrial case studies.

- Choosing and using a multi-criteria analysis method that attributes weights to the selected indicators.

- Integrating in the model a sort of natural environment sensitivity in order to balance the impacts with respect to the target.

\section{Acknowledgements}

The authors would like to thank the "Cluster Environment" of the Rhône-Alpes Region for its support. The collaborative partnership of the "Société Forezienne de Traitement de Surface" and "GalvaLoire" is also sincerely appreciated. The authors are thankful to Chris Yukna, for his help with English.

\section{References}

[1] UNEP; Cleaner production; www.unep.org; 2001. 
[2] Van Berkel R.; Cleaner production uptake in small to medium sized enterprises; Waste and Recycle Conference; http://cleanerproduction. curtin.edu.au; 2002.

[3] Laforest V.; Clean technologies: method for the outflow minimisation and the choice of effluents valorisation processes: Application to surface finishing workshops; thesis; pp 218; 1999. Available only in French.

[4] AERMC; Surface finishing: Water treatment; 2nd Edition; pp 287; ISBN 29506252-2-3; 2002. Available only in French.

[5] Gardes L.; Méthodologie d'analyse des dysfonctionnements des systèmes pour une meilleure maîtrise des risques industriels dans les PME: Application au secteur du traitement de surfaces; thèse.sci; pp 218; 2001. Available only in French

[6] Bouvier H., Gaudret De La Mauricière, G., Lê Quang X., Mahieu J. C., Perrin P. and Dimerman S.; finishing workshop: "Chemical risks prevention" health, security of people; 1998. Available only in French.

[7] Bonnard N., Falcy M. and Protois J. C.; Toxicological sheet of sodium cyanide and potassium cyanide FT 111; pp 6; www.inrs.fr; 2006.

[8] Laforest V., Cikankowitz A.; French legislative and institutional contexts: Application to the metal finishing sectors; report for the European "Zero Plus" project; 2006.

[9] Sire P.; The last evolution in the French regulation and the environmental constraints in the finishing sector; 2007.

[10] Ministerial order of June the $30^{\text {th }} 2006$, concerning finishing industries concerned by the authorisation (codification 2565); official newspaper $\mathrm{n}^{\circ} 205$ of $09 / 05 / 2006$.

[11] French Environment and Energy Management Agency; www.ademe.fr; 2007.

[12] Fijał T.; An environmental assessment method for cleaner production technologies; Journal of Cleaner Production; volume 15; pp 3; 2007.

[13] IEPF; Environmental impact evaluation; pp 102; www.iepf.org; 2003.

[14] Personne M.; Contribution à la méthodologie d'intégration de l'environnement dans les PME-PMI: Évaluation des performances environnementales; thèse.sci; pp 293; 1998. Available only in French.

[15] El Bouazzaoui I.; Un outil d'évaluation environnementale et de communication sur l'efficacité de l'entreprise dans sa démarche continue de réduction des impacts de ses activités industrielles; thèse.sci; 2008. Available only in French.

[16] International Organization for Standardisation; ISO 14040 Environmental Management Life cycle assessment Principles and framework; pp 14; 1997.

[17] Barthélémy B., Quibel J.; Risks management into enterprises; Techniques de l'ingénieur; ${ }^{\circ}$ AG 1100; pp 1-16; 2000. Available only in French.

[18] Charpulat V.; Vérification et validation de modèles de systèmes complexes: application à la Modélisation d'Entreprise; pp 136; 2007. Available only in French

[19] Desthieux G., Joerin F. and Lebreton M.; Systemic modelling tool of indicators. Application to urban diagnosis. pp 1-5; 2004. 
[20] Tyteca D.; Issue of environmental and sustainable development indicators; pp 15; www.isys.ucl.ac.be/working_papers/documents/WP72Tyteca.pdf; 2002. Available only in French.

[21] Repetti A.; Un concept de monitoring participatif au service des villes en développement. Approche méthodologique et réalisation d'un observatoire urbain; ${ }^{\circ} 2903 ;$ pp 1-220; 2004. Available only in French

[22] Perilhon P.; MOSAR: Presentation of the method; Techniques de l'ingénieur; SE 4061; pp 16; 2003. Available only in French.

[23] Muñoz F., Perrin L., Josien J. P., Chery O. and Sardin M.; The approach MADS/ MOSAR to manage the triptych "technology/normative/ management"; pp 24; 2007.

[24] Verdel T.; Risks assessment methodology: Potential application in civil engineering; Presses de l'ENPC; pp 23-28; ISSN 2-85978-334-2; 2000. Available only in French.

[25] EEA core set of indicators Guide; pp 1-38; ISSN 1725-2237; 2005.

[26] Veleva V., Hart M., Greiner T. and Crumbley C.; Indicators of sustainable production; Journal of Cleaner Production; volume 9; pp 447-452; 2001.

[27] WBCSD; Eco-efficiency Indicators: A tool for better decision making; pp $2 ; 1999$.

[28] Olsthoorn X., Tyteca D., Wehrmeyer W. and Wagner M.; Environmental indicators for business: a review of the literature and standardisation methods; Journal of Cleaner Production; volume 9; pp 453-463; 2001.

[29] Depoers F.; Reynaud E.; Maunoury G.S.; Sustainable development indicators; pp 139; http://www.agropolis.fr/formation/dd/nov04/idd_cer2d 06_2002.pdf; 2002. Available only in French.

[30] Cerrutti O., Gattino B.; Indicateurs et tableaux de bord; p 92; ISSN $0763-$ $6660 ; 1992$. 